\title{
ERRATUM TO: USING THE CRITERION-PREDICTOR FACTOR MODEL TO COMPUTE THE PROBABILITY OF DETECTING PREDICTION BIAS WITH ORDINARY LEAST SQUARES REGRESSION
}

\author{
SteVen AndRew CUlpepper
}

DEPARTMENT OF STATISTICS, UNIVERSITY OF ILLINOIS AT URBANA-CHAMPAIGN

\section{Errata to: PSYCHOMETRIKA, 2012, 77, 561-580 DOI 10.1007/s11336-012-9270-8}

\begin{abstract}
The Errata includes a corrected figure on the effect of group differences in common factor means and latent slopes on Type I error rates for ordinary least squares tests of intercept differences.
\end{abstract}

\section{Correction to Figure 2}

Culpepper (2012) examined the performance of ordinary least squares (OLS) as a method for assessing the presence of prediction bias (Millsap, 1997, 1998, 2007; Olivera-Aguilar \& Millsap, 2013). A seminar student at the University of Minnesota kindly pointed out an error in Figure 2 of Culpepper (2012). The error was clerical and the equations in the paper remain unchanged and correct. The purpose of this note is to correct Figure 2 in Culpepper related to the effect of group differences in common factor means (i.e., $\Delta \kappa$ ) and latent slopes (i.e., $\Delta \Gamma$ ) on Type I error rates of OLS tests of group intercept differences.

Recall from Culpepper (2012) that $Z$ and $Y$ represented the observed predictor and criterion, respectively, the number of applicants was indicated by $n$, the proportion in the focal group by $p$, and $P\left(Z>z^{\star}\right)$ was the percent of applicants selected in a top-down fashion. Furthermore, the latent measurement model parameters included $\Delta \phi$ as the difference in group common factor variances, $\Delta \xi$ as the difference in latent prediction error variance, $\theta_{z}$ and $\theta_{y}$ were the unique factor variances for the predictor and criterion, and the latent measurement intercept and loading was denoted by $\tau_{z}$ and $\lambda_{z}$ for the predictor and $\tau_{y}$ and $\lambda_{y}$ criterion. Figure 1 presents the corrected analytic (and Monte Carlo) Type I errors of tests for intercept differences across values of $\Delta \kappa$ and $\Delta \Gamma$ under the assumption of strict invariance with an $n=5,000, p=.8, P\left(Z>z^{\star}\right)=.5$, $\Delta \phi=0, \Delta \xi=0, \tau_{z}=\tau_{y}=.1, \lambda_{z}=\lambda_{y}=.8$, and $\Theta_{z}=\Theta_{y}=.2$. The dots around each of the Type I error curves in Figure 1 are the Monte Carlo estimates using 5,000 replications.

Figure 1 demonstrates the results pertaining to Millsap (1997, 1998, 2007) and Equation (30) of Culpepper (2012). Figure 1 shows that Type I error rates for intercept tests are larger than the real rejection level of .05 as $\Delta \kappa$ increases. For example, the probability of rejecting a true null hypothesis is approximately $50 \%$ when $\Delta \kappa=1$. In this case, larger latent subgroup slope

The online version of the original article can be found under doi:10.1007/s11336-012-9270-8.

Requests for reprints should be sent to Steven Andrew Culpepper, Department of Statistics, University of Illinois at Urbana-Champaign, 101 Illini Hall, MC-374, 725 South Wright Street, Champaign, IL 61820, USA. E-mail: sculpepp@illinois.edu 


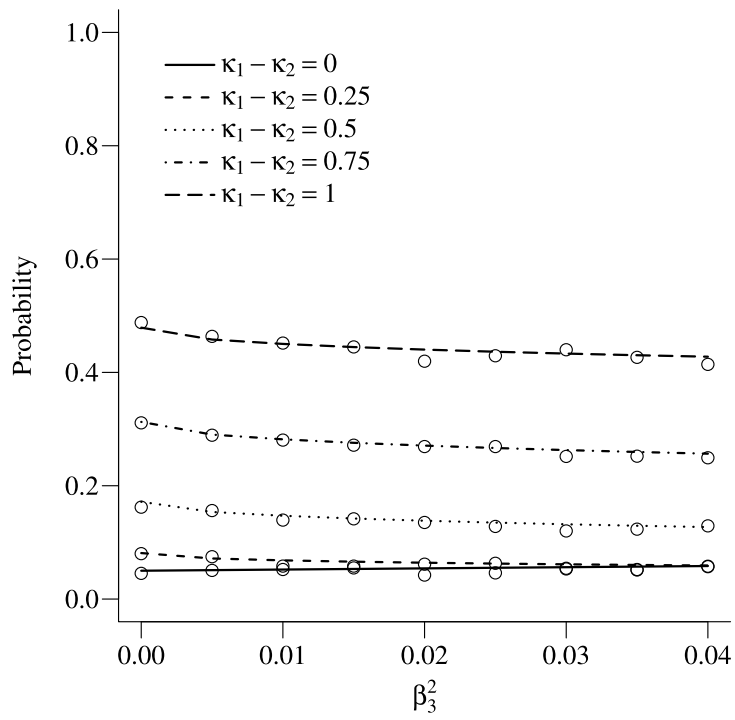

FIGURE 1.

Impact of $\Delta \kappa$ and latent slope differences $\left(\beta_{3}^{2}\right)$ on Type I error rates for tests of intercept differences. Note. The dots around each curve are Monte Carlo estimates using 5,000 replications.

differences (i.e., $\beta_{3}^{2}$ ) slightly reduces intercept Type I error rates. In short, Figure 1 demonstrates that OLS is an inadequate method for testing the presence of subgroup intercept differences whenever groups differ in common factor means.

\section{References}

Culpepper, S.A. (2012). Using the criterion-predictor factor model to compute the probability of detecting prediction bias with ordinary least squares regression. Psychometrika, 77, 561-580.

Millsap, R.E. (1997). Invariance in measurement and prediction: Their relationship in the single-factor case. Psychological Methods, 2, 248-260.

Millsap, R.E. (1998). Group differences in regression intercepts: Implications for factorial invariance. Multivariate Behavioral Research, 33, 403-424.

Millsap, R.E. (2007). Invariance in measurement and prediction revisited. Psychometrika, 72, 461-473.

Olivera-Aguilar, M., \& Millsap, R. (2013). Statistical power for a simultaneous test of factorial and predictive invariance. Multivariate Behavioral Research, 48, 96-116.

Published Online Date: 5 JUN 2013 